Supplementary data for: 'Organocatalysis of Asymmetric Epoxidation Mediated by Iminium Salts under Non-Aqueous Conditions'

Philip C. Bulman Page,* David Barros, Benjamin R. Buckley, Adel Ardakani, Brian A. Marples

\title{
Contents
}

Experimental procedure for the preparation of tetraphenylphosphonium monoperoxysulfate (TPPP)

General procedure for the catalytic asymmetric epoxidation of simple alkenes mediated by iminium salts using TPPP 


\section{Tetraphenylphosphonium monoperoxysulfate}

Oxone triple salt $\left(2 \mathrm{KHSO}_{5}: \mathrm{KHSO}_{4}: \mathrm{K}_{2} \mathrm{SO}_{4}\right)\left(15.0 \mathrm{~g}, 48.8 \mathrm{mmol}\right.$ w.r.t. $\left.\mathrm{KHSO}_{5}\right)$ was dissolved in deionised water $(300 \mathrm{ml})$ with magnetic stirring at $10-15^{\circ} \mathrm{C}$ (water bath). Tetraphenylphosphonium chloride $(15.0 \mathrm{~g}, 40.0 \mathrm{mmol})$ in distilled dichloromethane (300 $\mathrm{ml})$ was gradually added over $5 \mathrm{~min}$. After an additional $30 \mathrm{~min}$, the organic layer was separated, and solvent was removed under reduced pressure to afford a colourless solid. The crude salt was transferred to a fritted glass funnel and washed with distilled water $(2 \times 75 \mathrm{ml})$. The solid which remained was recrystallized from dichloromethane/hexane to afford colourless crystals, containing about $85 \%$ available oxygen $(15.4 \mathrm{~g}, 70 \%) . \delta_{\mathrm{H}}\left(250 \mathrm{MHz} ; \mathrm{CDCl}_{3}\right) 7.64(8 \mathrm{H}, \mathrm{m})$, $7.78(8 \mathrm{H}, \mathrm{m}), 7.89(4 \mathrm{H}, \mathrm{m}), 8.92(1 \mathrm{H}, \mathrm{s})$.

\section{General procedure for catalytic asymmetric epoxidation of simple alkenes mediated by iminium salts using tetraphenylphosphonium monoperoxysulfate}

Tetraphenylphosphonium monoperoxysulfate ( 2 eq with respect to the substrate) was dissolved in the desired solvent $(2 \mathrm{ml}$ per $0.1 \mathrm{~g}$ oxidant) and cooled to the required temperature. To this was added the iminium salt as a solution in the solvent $(0.5 \mathrm{ml}$ per $0.1 \mathrm{~g}$ oxidant). This iminium salt solution was cooled to the same temperature as the solution containing the oxidant and added dropwise to it over 15-20 min; the temperature of the reaction vessel was monitored to minimize increase in temperature during the addition. The substrate $(100 \mathrm{~mol} \%)$ was added as a solution in the reaction solvent $(0.5 \mathrm{ml}$ per $0.1 \mathrm{~g}$ oxidant $)$ in the same manner as the catalyst. The reaction was stirred at the same temperature until the substrate was completely consumed by TLC. Diethyl ether (pre-cooled to the reaction temperature) $(20 \mathrm{ml}$ per 0.1 g oxidant) was added to precipitate the remaining oxidant. The solution was filtered through Celite, and the solvents removed under reduced pressure to give the epoxide product. Pure samples were obtained by column chromatography, eluting with ethyl acetate/light petroleum (1:99). 